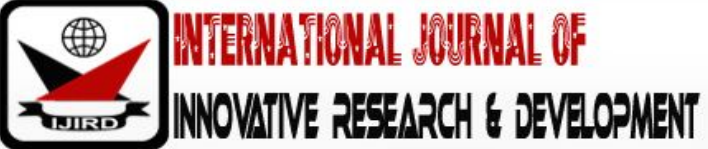

ISSN 2278 - 0211 (Online)

\section{Perception of Youth on Transgender Individuals: A Case of Kumasi, Ghana}

\begin{tabular}{c}
\hline Dr. Francess Dufie Azumah \\
Lecturer, Department of Sociology and Social Work, \\
Kwame Nkrumah University of Science and Technology, Ghana \\
Michelle Kyei-Donkor \\
Student, Department of Sociology and Social Work, \\
Kwame Nkrumah University of Science and Technology, Ghana \\
Samuel Krampah \\
Teaching and Research Assistant, Department of Sociology and Social Work, \\
Kwame Nkrumah University of Science and Technology, Ghana \\
John Onzaberigu Nachinaab \\
Ph.D. Candidate, Department of Sociology and Social Work, \\
Kwame Nkrumah University of Science and Technology, Ghana
\end{tabular}

\begin{abstract}
:
Issues of transgender have become more salient in the present-day world. While transgender individuals make up the small minority of the world's population, their right and treatment by society sit at the front of civil right debates. This study examined the perception of youth on transgender individuals. The objectives of this study were to examine youths' perception on transgender and transgender individuals, explore the factors contributing to transgender and examine the issues or effects transgender people face. A case study design was utilized for study. Probability sampling, specifically, the simple random sampling technique was used to select 240 students (undergraduates and postgraduates) as respondents for this study. Data was collected by the use of questionnaire. Findings of this study revealed that majority of respondents knew about transgender and transgender individuals. A chi-square test for independence was utilized to determine the relationship between transgender and transgender individuals and the effects or issues they experience. The Chi-square analysis indicated a statistical significant relationship between the existence of transgender and transgender individuals and gender dysphoria (effects or issues transgender individuals face) at alpha level $5 \%, \mathrm{X}^{2}=17.252, \mathrm{df}=8, \mathrm{~N}=240$ and $\mathrm{p}$-value $\varangle 0.028$. That is, transgender individuals are indeed confronted with gender dysphoria. However, $5 \%$ of the time we may be wrong in our computation.
\end{abstract}

Keywords: Transgender, transgender individuals, youth, stigmatization, discrimination, cultural transformation

\section{Introduction}

Transgender is a worldwide marvel. The term transgender was begat by John F. Oliven, a popular specialist of Columbia College in his 1965 reference work, Sexual Hygiene and Pathology. He sets that the past term transsexual is deluding. This is on the grounds that sexuality is not a prevalent factor in essential transvestism (Oliven, 1965).In most developments, transgender existed yet its comprehension was distinctive at different time frames.

All through Europe, Asia, the Center East and Northern Africa, clans of various sorts worshiped what they recognized as "The Great Mother". The Roman history specialist Plutarch delineates "The Great Mother" as an intersex god from whom the two genders had not yet part. In Europe, a cupid was a double god or goddess of affection, initially depicted as intersex. Narrowing down to Africa, there are accounts of intersex gods and profound convictions in sexual orientation change in Akan, Dahomean (Benin) and through a few West African religions. Late investigations have portrayed that the twofold idea of sex being just male or female is changing, and that there are as of now different perspectives on how sex is experienced. Sexual orientation is viewed as a liquid, perplexing and faulty idea (Connell, 2002).

People normally have the power and the will to settle on a few decisions concerning their lives. For this situation, because of innovation and mechanical progression, individuals can go beyond what many would consider possible to settle on subjective choices on their sexual orientations. Few people may want to change their sexual orientation, since they are miserable with their unique sex, hence, experiencing sex dysphoria. In any case, as per the U.S. Branch of State's 2012 Human Rights Report found that, transgendered people are confronted across the board segregation, and also police provocation and coercion endeavors. This clarifies the way that, transgendered people do not have any type of sacred sponsorship concerning their rights and this is risky. 
It is along these lines vital for this examination to be led to help set up youth's perception on transgender and transgendered individuals. Few people may choose not to change their sex for partisan reasons or just in light of the fact that they trust it is deceptive and generally their societies disapprove of it. This is to state that transgender does not have culture acknowledgment in many nations. For instance, In November 2014, A New York Based Association gave a helping hand to Russian LGBT individuals who left Russia. This was on the grounds that Russian culture does not favor transgender and subsequently transgendered people are not acknowledged.

There are differing seen suggestions or impacts of transgender on transgendered individuals. Individuals who have changed their sex are confronted with social disgrace (Herman, 2013), encounters of segregation (Grant et al., 2011) and are confronted with physical and mental savagery (Lombardi et al., 2002). These encounters have connections to suicide among transgender individuals (Clements-Nolle, Marx \& Katz 2006). However, findings from the National Transgender Segregation Overview, a vast accommodation test of transgender individuals, recommend that rates of transgender separation are high: around $78 \%$ of those studied report encounter coordinate abuse or separation in the work environment (Grant et al. 2011).

Likewise, the sentiment blame is another impact of transgender on transgender individuals. Schaefer (2004) took a gander at blame, a considerable measure of transgender individuals feels in connection to their cross-sexual orientation inclinations. Information was accumulated on 787 patients and discovered 13 topics of blame. Blame is frequently the persuading factor that directs how sexual orientation bothered people translate, oversee, and experience their lives (Schaefer, 2004). This enabled the researchers to look at the perception of youth' on transgender and transgender individuals.

\subsection{Research Objectives} individuals.

The overall objective of the study is to examine the perception of youth' on transgender and transgender Specifically, the study seeks to:

- Examine youths' perception on transgender and transgender individuals.

- Explore the factors contributing to transgender.

- Examine the issues or effects transgender people face.

\section{Literature Review, Theoretical Perspective and Conceptual Framew ork}

As indicated by the consequences of a national study discharged at the Southern Comfort Transgender Meeting in Atlanta (2002) 7 out of 10 individuals incorporated into the report, "Open Impression of Transgender Individuals," said they know about the word transgender. A greater part of respondents trust it is "OK" to be transgendered. $50 \%$ of those overviewed accept transgendered grown-ups ought to be permitted to instruct in secondary schools, however just around $40 \%$ trust they ought to be permitted to be grade school, rec center class, or day mind instructors or exploring pioneers. $74 \%$ say they would be alright working with a transgendered individual; $61 \%$ support laws to avert working environment segregation; and $68 \%$ help detest wrongdoings laws that cover transgendered individuals. After respondents were given the meaning of being transgendered-an activity that is viewed as a curtailed type of training they had to some degree less ideal state of mind toward transgendered individuals. Furthermore, the survey found an extremely basic connection between whether general society sees being transgender as an ethical issue and whether they think individuals have a decision about being a transgender. A survey conducted by the Human Rights Campaign Foundation (2002) on transgender demonstrated that $61 \%$ of Americans trust that the nation needs laws to shield transgender individuals from segregation. It is assessed that no less than 15 transgender individuals are murdered every year in detest based assaults, despite the fact that this number might be higher in view of transgender individuals' regular dread of setting off to the police and far reaching distorting. Medley (2005) explored the states of mind towards gay, lesbian, bisexual and transgender individuals from the perspective of hetero guys who went to private foundations. Respondents' dispositions were slightly constructive toward transgender individuals.

It is imperative to take note that, few people are in help of the Constitutional zing of transgendered rights, as a 2011 Open Religion Exploration Establishment Overview of American grown-ups reports that respondents who trust themselves conversely, joins reactions to three proclamations about transgender rights into a solitary ward variable (Flores, 2015). Transgender individuals merit an indistinguishable rights and insurances from different Americans; legitimate securities that apply to gay and lesbian individuals ought to likewise apply to transgender individuals; and congress should pass laws to shield transgender individuals from segregation. The exploration likewise finds that respondents who have had earlier contact with individuals of the LGBT people group are all the more positively arranged toward transgender rights. A possible instrument is that recognition produces a type of para-social contact, which relates with sympathy and state of mind change (Batson et al., 1997). This depicts the impression of a few people who are in help of the Constitutional zing of the privileges of transgendered people. In any case, it is not everybody who is in help of the Constitutional zing of the privileges of transgendered people. A Shadow Provide details regarding Human Rights Infringement against Lesbian, Gay, Bisexual, and Transgender (LGBT) Individuals in Ghana, submitted for thought at the 115th Session of the Human Rights Panel in October 2015 in Geneva, put together by Solace Brothers Foundation. The Initiative for Equal Rights, Center for International Human Rights of Northwestern University School of Law and Heartland Alliance for Human Needs \& Human Rights Global Initiative for Sexuality and Human Rights in August 2015 expressed completely that, Articles 19(2), 21, and 22 of the Agreement is to secure the opportunity to express thoughts and bestow data, the flexibility to calmly collect, and the opportunity to connect with others. In Ghana, LGBT people and LGBT rights advocates are liable to fierce assaults and threatening vibe. Hubbub resulted when, in July 2012, Ghana's Constitution 
Audit Bonus suggested that Ghana's Preeminent Court settle on whether the nation ought to sanction LGBT acts. More than $98 \%$ of the entries were gotten by the commission against LGBT rights. Inborn pioneers, government authorities and even individuals from the Commission transparently condemned the proposal, calling the LGBT hone as "un-African" and "ethically hostile." Once more, Physical assaults against LGBT people in Ghana damage rights ensured by Articles 7 and 9 of the Contract. Article 7 secures against torment and barbarous, brutal or debasing treatment. Article 9 guarantees security of individual. Ghana's Agreement commitment is to guarantee the insurance of these rights by advancing consistence and forestalling, examining, arraigning, rebuffing, and helping infringement. Ghana has not consented to these commitments. Acquittal Global and the NGO Flexibility House detailed in 2013 that savagery against the LGBT people group was common and that the abuse of sexual minorities has risen.

\subsection{Theoretical Perspective}

In this article, the cultural studies theory will be utilized. The perception that media influence is the major reason for people changing their gender. Cultural studies theories look to explain media's influence on our society from an overwhelming cultural perspective where the media is a powerful influence in our cultural and social life, generally controlled in large part by those who are dominant in society. Therefore, marginalized groups who do not have this power are even further underrepresented and their marginalization is reinforced via the media. Hall (1982) links this concept of ideology to social practices, because he strongly believes that things and occasions do not contain meaning freely of dialect. Past that, philosophies are not single thoughts but rather are associated with one thought setting off a "chain of indicative affiliations" (Hall, 1985, p. 104). Therefore, it is perceived that, due to the illusionary idealistic culture portrayed by the media, it influences the idea of changing one's gender, as the mass media is sociologically referred to as a mediated culture.

Looking at Gramsci's (1971) concept of hegemony, ideology can be understood. Hegemony explains the prominent values, states of mind, convictions and profound quality that penetrates society bringing about ideological and social power applied by a predominant gathering (Gramsci, 1971). Since its invasion is seen as the standard, it turns into a piece of what is viewed as good judgment and the regular request of things, prompting the way of life and ethical quality of the decision class to manage regularizing logic, culture and profound quality (Boggs, 1976). Gramsci guesses that authority is a, "procedure, a consistent battle to characterize presence of mind understandings inside a culture" (Loke, Harp and Bachmann, 2010). Truth be told, "authority, or any type of verbalization, is never last or aggregate" which implies that rethinking the standard is a plausibility (Carpentier \& Cammaerts, 2006; p. 966). The ideology that is typically seen in the media about a marginalized group like the LGBT community, most especially, transgender individuals is one that has illustrated the dominant group's ideas. However, hegemony is a process and ideas can constantly be redefined and modified.

\subsection{Conceptual Framework}

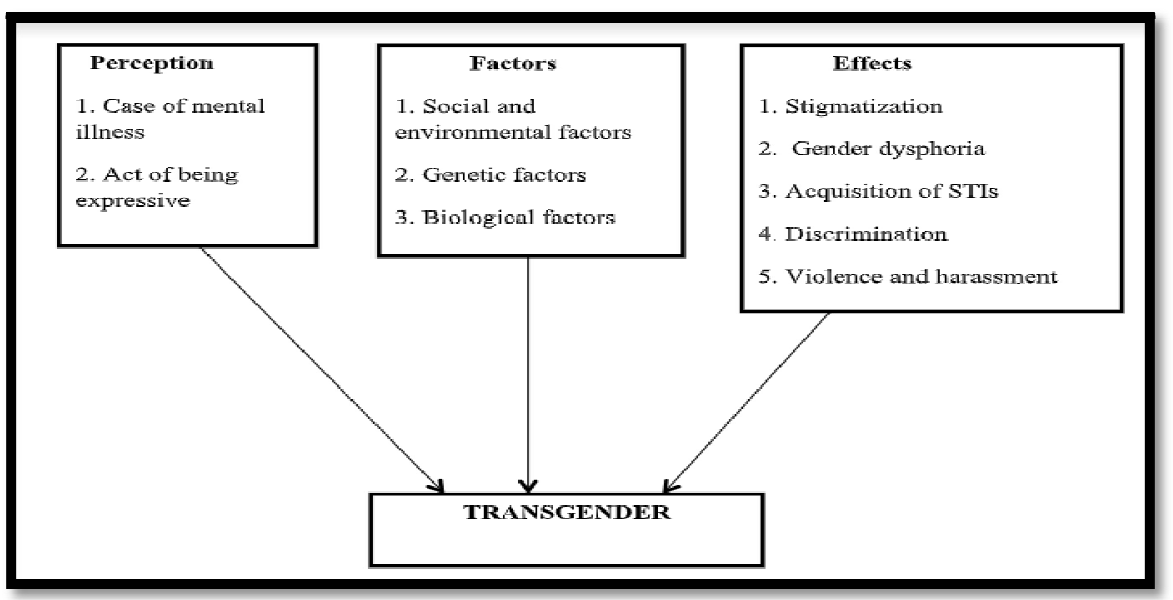

Figure 1: Conceptual Framework of Perception of Youth' on Transgender and

Transgender Individuals

Source: Researchers Own Construct (2018)

The conceptual framework above shows the pictorial presentation of the study. From the figure, it can be seen that transgender being a case of mental illness and an act of being expressive is what most youth' perceive transgender to be. However, several factors contribute to the change in one's gender and these are social and environmental factors, genetic factors and biological factors. Individuals who undergo transgender are faced or confronted with several effects or issues and these are gender dysphoria, stigmatization, and acquisition of STIs, discrimination and violence and harassment.

\section{Methodology}

This aspect of the study dealt with the various techniques, methods and tools the researchers employed in collection and analysis of data and evaluating and making conclusion of results. It was an embodiment of the various steps that were generally adopted by the researchers in studying the research problem. 


\subsection{Research Design and Type of Study}

The study adopted the case study design to provide intensive empirical data. Case study design was utilized to describe the methods for the gathering of information, formulation and for the collection of primary data. Quantitative method was employed for this study. This was because a large sample of data was needed to be used for the study and to deduce from the sample and make a generalization. Quantitative method covered a broad range of statistical gathering techniques that were all focused on getting numerical data for statistical analysis.

\subsection{Sampling Technique and Sample Size}

The probability sampling method was utilized for the research. Specifically, the study used the simple random technique. The simple random sampling technique indicated the likelihood that each sampling unit incorporated into the sample unit had an equivalent possibility of consideration in the sample. It was likewise advantageous to use than other sampling techniques with respect to extensive population size. The simple random sampling particularly was utilized as part of choosing the sampling units since it guarantees that the students populace had an equivalent and known likelihood of being incorporated into the sample. However, since all the student's populace cannot be utilized for the study, a sample size of 240 (undergraduates and postgraduates) students from the various colleges in Kwame Nkrumah University of Science and Technology (KNUST) were utilized for the study.

\subsection{Data Collection Method}

Questionnaire was the main tool for the collection of primary data. The questionnaire comprising only close-ended items were administered to the respondents. The close-ended questions offered alternatives from which the respondents in the study chose the answers they esteem suitable. The questions were used to achieve the objectives of the study. The questionnaires were largely administered by the researchers through face-to-face sessions with respondents.

\subsection{Data Analysis Method}

The quantitative data collected through the use of questionnaire were organized by the use of the Statistical Package for Social Sciences (SPSS version 22) for detailed analysis. Both descriptive and inferential statistics were utilized

\subsection{Ethical Considerations}

The primary area of ethical issues that the researchers considered incorporated the informed consent, invasion of privacy, anonymity and confidentiality.

\section{Results of the Study}

\subsection{Socio-Demographic Characteristics of Respondents}

Findings of the study revealed that males dominated the study and this could be attributed to the fact KNUST has males as its majority of students. It thus shows the true characteristics of gender percentage of students on KNUST campus. It was also revealed that majority of the respondents were between the ages of 21-24. This is in agreement to the national enrollment which asserts that the average age of pupil in the university is between 18 and 25 (GDHS, 2014). In terms of religious affiliation, it was revealed that respondents were evenly distributed among the two main religions in Ghana, which are Christianity and Islam respectively. This could be attributed to the fact that the study was conducted on an Akan land (Kumasi) where most of the students are Christians because the KNUST is situated in Kumasi, Ghana. Most of the respondents were found to be undergraduates and this clearly shows that undergraduate students have higher student populace than postgraduates in KNUST. It was also revealed that majority of the respondents were from the Akan ethnic group. This could be attributed to the fact that KNUST is situated in Kumasi which is mostly dominated by the Akans.

\subsection{Perception of Youth' on Transgender and Transgender Individuals}

The study sought to examine the perception of youth' on transgender and transgendered individuals. Respondents were asked whether transgender and transgendered individuals exist and it was revealed that $75.8 \%$ of the respondents indicated that transgender and transgendered individuals exist whiles $24.2 \%$ indicated that transgender and transgendered individuals do not exist. It was found that majority of the respondents indicated that main perception by youth' on transgender and transgendered individual was that of youth' interest in issues of transgender with a mean score of 3.52. This was followed by youths' emulation of celebrities and prominent people who are transgender which recorded a mean score of 3.43. The third was that of mental illness disorder which had a mean score of 3.21. However, transgender as an act of being expressive recorded the fourth highest means score of 3.18. The least among the youths' perception on transgender and transgendered individuals was youths' support for transgender and transgendered individuals with a mean score of 3.03 respectively.

\subsection{Factors That Contributes to Transgender}

The study sought to find out the factors contributing to the transformation of one's gender. Findings revealed that majority of the respondents indicated that the major factor that contributes to the transformation of one's gender was that of biological factors with a mean score of 3.58. However, genetic factor was seen as the second factor contributing to the transformation in one's gender having a mean score of 3.51. Environmental factor recorded the least factor contributing to the transformation of one's gender having a mean score of 3.35. Biological factor seen as the major factor contributing to transgender concur Sarasw at et al. (2015) study on biological nature of gender identity. 


\subsection{Effects or Issues Transgender Individuals Face}

The study sought to examine the effects or issues transgendered individuals face. Findings of the study revealed that majority indicated that the main effect or issue transgendered individuals face is that of gender dysphoria with a mean score of 3.78. Stigmatization which recorded a mean score of 3.53 was seen as the second effect or issue. Violence and harassment recorded that third major effect or issue which had a mean score of 3.44. However, acquisition of STIs recorded the fourth highest means score of 3.40. The least among the effects or issues was that of discrimination with a mean score of 3.27 respectively. Majority asserting that the major effect is gender dysphoria could take a cue from Curtis et al. (2009) who asserts that transgender people have gender identity that does not match their assigned sex, often resulting in gender dysphoria.

To determine the relationship between the existence of transgender and transgender individuals and gender dysphoria (effects or issues transgender individuals face), chi-square test for independence was conducted. The Chisquare analysis indicated a statistical significant relationship between the existence of transgender and transgender individuals and gender dysphoria (effects or issues transgender individuals face) at alpha level $5 \%, \mathrm{X}^{2}=17.252, \mathrm{df}=8$, $\mathrm{N}=240$ and $\mathrm{p}$-value $<0.028$. That is, transgender individuals are indeed confronted with gender dysphoria. However, $5 \%$ of the time we may be wrong in our computation.

\section{Recommendations} problem.

Based on the findings of the study, the researchers suggested the following recommendations to address the

The researchers recommended that Government must play a role in enlightening Ghanaians on issues on transgender and its associated effects. This can be done through open forums or discussions on television and radio.

The researchers again recommended that proper clarifications need to be done by Government and policy makers on the constitutional zing and legalization of the rights of transgender individuals and its accompanied sanctions so as to be able to apply the appropriate punishments on deviants when necessary.

Finally, the Government and citizens of Ghana must put into account the advantages and disadvantages of legalizing transgender in the country, in their quest to either legalize or not to legalize it so as to be able ascertain the fact that, it may or may not cause any form of cultural or religious conflicts as well as the disruption of the country's relationship with other countries.

\section{Conclusions}

Issues of transgender have become more salient in the present-day world. While transgender individuals make up the small minority of the world's population, their right and treatment by society sit at the front of civil right debates. Findings of the study revealed that transgender individuals do exist but most people have not seen one physically unless through the internet and other means. In the quest to find out the perception the youth has on transgender and transgender individuals, it was revealed that most youth have interest in the issues of transgender. With regards to factors contributing to transgender, it was revealed that biological factor was seen as the major factor contributing to transgender. Lastly, in the pursuit to find out the effects or issues facing transgender individuals, the findings revealed that gender dysphoria was the major effect or issue transgender individuals are mostly confronted with.

\section{References}

i. Batson, C. D., Polycarpou, M. P., Harmon-Jones, E., Imhoff, H. J., Mitchener, E. C., Bednar, L. L., .. . Highberger, L. (1997). Empathy and attitudes: Can feeling for a member of a stigmatized group improve feelings toward the group? Journal of Personality and Social Psychology, 72(1), 105-118. http://dx.doi.org/ 10.1037/ 00223514.72.1.105

ii. Boggs, C. (1976). Gramsci's Marxism. London: Pluto Press.

iii. Carpentier, N., \& Cammaerts, B. (2006). "Hegemony, Democracy, Agonism, Journalism; An interview with Chantal Mouffe. In Journalism Studies (pp. 7(6), 964-75).

iv. Clements-Nolle, K., Marx, R.\& Katz, M. (2006). Attempted suicide among transgender persons: The influence of gender-based discrimination and victimization. J Homosex, 51 (3), 53-69.

v. Connell, R. W. (2002). Gender. Cambridge: Polity Press.

vi. Flores, A. R. (2015). Attitudes toward transgender rights: perceived knowledge and secondary interpersonal contact.

vii. Gramsci, A. (1971). Selections from the Prison Notebooks. New York: International Publishers.

viii. Grant, J., Mottet, L., \& Tanis, J. (2011). "Injustice at Every Turn: A Report of the National Transgender Discrimination Survey.". Retrieved from National Center for Transgender Equality http:/ / www.transequality.org/ issues/ resources/ national-transgender-

ix. Hall, S. (1982). "The Rediscovery of 'Ideology' : Return of the Repressed in Media Studies". In M. Gurevitch, T. Bennett, J. Curran, \&J. Woollacott, Culture, Society and the Media, 56-90. New York, Methuen.

x. Hall, S. (1985). Critical Studies in Mass Communication. In "Signification, Representation, Ideology": Althusser and the Post-structuralist Debates, 91-114.

xi. Herman, J. L. (2013, June). Gendered Restrooms and Minority Stress: The Public Regulation of Gender and its Impact on Transgender People's Lives. Retrieved from The Williams Institute, UCLA SCHOOL OF LAW: https:/ / williamsinstitute.law.ucla.edu/ research/ transgender-issues/ herman-jpmss-june-2013/ 
xii. Loke, J., Harp, D., \& Bachman, I. (2010). Mothering and Governing: How News Articulated Gender Roles in the Cases of Governors, Jane Swift and Sarah Palin . In Journalism Studies, 12(2), 205-220.

xiii. Lombardi, E., Wilchins, R., Priesing, D., \& Malouf, D. (2001). Transgender Experiences With Violence and Discrimination. Journal of Homosexuality, Vol. 42(1), 89-101.

xiv. Medley. (2005). A Study of Attitude of Society towards Transgender in South India. Retrieved from https:/ / www.ijsr.net>ART20176251

xv. Oliven, J. F. (1965). Transgender (3rd Ed.). Sexual Hygiene and Pathology

xvi. Saraswat, A., Weinand, M., \& Safer, J. D. (2015). Evidence Supporting the Biologic Nature of Gender Identity. Endocrine Practice, 1(1), 1-20

xvii. Schaefer, L. W. (2004). Guilt in cross gender identity conditions: presentations and treatment. Journal of Gay and Lesbian Psychotherapy, 8 (1/2), 117-127.

\begin{tabular}{|c|c|c|c|}
\hline Variables & Categories & Frequency (N) & Percent (\%) \\
\hline \multirow[t]{3}{*}{ Gender of Respondents } & Male & 144 & 60.0 \\
\hline & Female & 96 & 40.0 \\
\hline & Total & 240 & 100.0 \\
\hline \multirow[t]{4}{*}{ Age of Respondents } & $17-20$ & 46 & 19.2 \\
\hline & $21-24$ & 150 & 62.5 \\
\hline & $25-28$ & 44 & 18.3 \\
\hline & Total & 240 & 100.0 \\
\hline \multirow{4}{*}{ Religious affiliation of Respondents } & Christian & 180 & 75.0 \\
\hline & Muslim & 58 & 24.2 \\
\hline & Traditionalist & 2 & 0.8 \\
\hline & Total & 240 & 100.0 \\
\hline \multirow[t]{3}{*}{ Level of education of Respondents } & Undergraduate & 186 & 77.5 \\
\hline & Postgraduate & 54 & 22.5 \\
\hline & Total & 240 & 100.00 \\
\hline \multirow[t]{5}{*}{ Ethnicity of Respondents } & Akan & 98 & 40.8 \\
\hline & $\mathrm{Ga}$ & 56 & 23.3 \\
\hline & Ewe & 50 & 20.8 \\
\hline & Hausa & 36 & 15.1 \\
\hline & Total & 240 & 100.0 \\
\hline
\end{tabular}

Table 1: Socio-Demographic Characteristics of Respondents

Field Survey Result, 2018

\begin{tabular}{|c|c|c|c|c|}
\hline Statement & $\mathbf{N}$ & Mean & Ranking & Standard deviation \\
\hline Interest in issues of transgender & 240 & 3.52 & $1^{\text {st }}$ & 0.116 \\
\hline $\begin{array}{c}\text { Support for transgender and transgendered } \\
\text { individuals }\end{array}$ & 240 & 3.03 & $5^{\text {th }}$ & 0.134 \\
\hline $\begin{array}{c}\text { Act of being expressive } \\
\begin{array}{c}\text { Emulation of celebrities and prominent people } \\
\text { who are transgender }\end{array}\end{array}$ & 240 & 3.18 & $4^{\text {th }}$ & 0.108 \\
\hline Result of mental illness & 240 & 3.43 & $2^{\text {nd }}$ & 0.103 \\
\hline
\end{tabular}

Table 2: Perception of Youth' on Transgender and Transgender Individuals

Field Result Survey, 2018

\begin{tabular}{|c|c|c|c|c|}
\hline Statement & $\mathbf{N}$ & Mean & Ranking & Standard deviation \\
\hline Biological factors & 240 & 3.58 & $1^{\text {st }}$ & 1.157 \\
\hline Genetic factors & 240 & 3.51 & $2^{\text {nd }}$ & 1.145 \\
\hline Social or environmental factors & 240 & 3.35 & $3^{\text {rd }}$ & 1.074 \\
\hline
\end{tabular}

Table 3: Factors that Contributes to Transgender

Filed Survey Results, 2018

\begin{tabular}{|c|c|c|c|c|}
\hline Statement & $\mathbf{N}$ & Mean & Ranking & Standard deviation \\
\hline Gender dysphoria & 240 & 3.78 & $1^{\text {st }}$ & 0.991 \\
\hline Stigmatization & 240 & 3.53 & $2^{\text {nd }}$ & 1.230 \\
\hline Violence and harassment & 240 & 3.44 & $3^{\text {rd }}$ & 1.295 \\
\hline Acquisition of STIs & 240 & 3.40 & $4^{\text {th }}$ & 1.095 \\
\hline Discrimination & 240 & 3.27 & $5^{\text {th }}$ & 1.235 \\
\hline
\end{tabular}

Table 4: Effects or Issues Transgendered Individuals Face

Field Survey Results, 2018 